\title{
Positive Correlation of Personality Traits on Test Score in Learners of Frontrunner 7 Class in EF English First Kayun Surabaya
}

\author{
Belinda Devina \\ Graduated from English Department Universitas Airlangga $\backslash$ \\ An English Teacher in EF English First Surabaya \\ Surabaya, Indonesia \\ beldevina@gmail.com
}

\begin{abstract}
English has great impact in the movement of the world, for example in education matter, like science. In learning English, motivation is needed in order to reach the successful learning. Reference [1] argued that motivation involves attitude and affective states that influence the degree of effort that learners make to learn an L2. According to Troike (2012), personality factors are sometimes added to cognitive style in characterizing more general learning style, which can lead to the success of $\mathrm{L} 2$ learning. This study involves three students from Frontrunner 7 class of EF Kayun Surabaya. In obtaining the data, observation and library research methods were taken. The result revealed that the students' successful learning is affected by their attitude and personality in class, as stated by [4]. The writer could find each characters mentioned by [4] in each participants. First, Danny who got the best score in class is imaginative and adventuresome based on the observation. Second, Egi who got the second best score in class is selfconfident and risk taking. Last, Dewi who got the third best score in class is tolerant of ambiguity.
\end{abstract}

\section{Keywords—personality; test score; EF Kayun; Troike}

\section{INTRODUCTION}

English is spoken by most of people in the world, either as the first, second, or foreign language. Also, it is common to use English as lingua franca when we are talking with people from different country, even when they are from non-English speaking country. English has great impact in the movement of the world, for example for education matter, like science. There are several terms of science which are mostly used English as the language. Compared to China, even though the number of people is greater than English, English is still on the top as the most speaking language. Based on [4], approximately 6,000 languages are spoken in all around the world. The four most commonly used languages are Chinese, English, Spanish, and Hindi. He argued that even though Chinese is an L1 for many people than any other language, English is by far for the most common language for the L2. The data showed that Chinese has over one billion 200 million people used it as L1, but only fifteen millions learn it as L2. While English has only 427 million L1 speakers, but the number of the L2 speakers is just outrageous, it reaches the number of 950 million. Of course if we sum up, English definitely has greater number of speakers.
This paper will analyze the learning process of foreign language, which is English by Indonesian learners. The objects that will be taken are those who become student of Frontrunner 7 level in EF English First Surabaya for Saturday 12.30PM class. The aim of this paper is going to be how high motivation, personality, along with either positive or negative attitudes can help them to get success in learning foreign language. The writer will only focus on the certain class stated, because EF English First Kayun has numbers of Frontrunner 7 class, and also the writer will take several students as the sample for the analysis.

Motivation and personality is often related on how learners respond to the input of a certain language. When leaner is learning, the way they react to the stimulus given by the teacher is sometimes determined their success in learning itself. The common argument stated that when learners are highly motivated, having tendency to be talk active and seriously focused on what they are learning, they will be success on the language learning. Some of the experts below argue that there are several components which impact the learners in learning language. Reference [4] stated that, personality factors are sometimes added to cognitive style in characterizing more general learning style. She added that there are several personality traits which indicate positive correlation with the success of L2 learning; self-confident, risk-taking, adventuresome, imaginative, and tolerant of ambiguity. Meanwhile, talking about motivation, reference [1] argued that motivation involves attitude and affective states that influence the degree of effort that learners make to learn an L2. He elaborated more that there are four types of motivation, there are instrumental motivation which is related to learners' functional reason like passing an exam, getting a better job, and getting a place in University, integrative motivation, which is related to learners' personal interest towards a certain culture, resultative motivation, which is related to the motivation that becomes the main cause of the learning, and intrinsic motivation.

The writer adapts library research method to conduct the further analysis for this paper. The source will be related to study about the L2 learners' motivation and personality to the success of learning. The writer also conducted the quantitative research. Based on [3], quantitative research here can be meant as measuring learners' scores based on the language test performance. In this case, the writer will use the students' progress to measure how success the learners learn the L2. The writer will also do an observation to the students' classroom activity for six meetings every Saturday, starting from 25 April 2015 until 13 June 2015. There are nine students in the class, 
but the writer will only take three students to be examined. The sample of the students will be taken randomly.

\section{ANALYSIS}

As stated in the previous part, that the purpose of this analysis is to describe how motivation and attitude affect the successful L2 learning. In this case, the writer uses the progress as the variable of measurement of "success" for each student. Among nine students in the class, the writer will only take three students to be the objects for this analysis. The students' named are Egi, Danny, and Dewi. All of them are senior high school students. Dewi and Egi are in the eleventh grade of senior high school, while Danny is currently in the tenth grade of senior high school. Considering the background of the students, we can imply that their motivation of learning English will be something related to school. Therefore it is included in the instrumental motivation. The other personal motivation of each student will be explained in the next part of the analysis. The writer observed the process of language learning for about six meeting, starting from 25 April to 13 June 2015 every Saturday.

When the writer first met the students, she could directly see that Egi was a very cheerful and active student. She always showed her interest every time she met new teacher. It is very different with Danny. He seemed shy and afraid to make eye contact. Dewi's attitude was also the same as Egi, but she looked a bit shy. The writer first assumed that there is combination between Egi and Danny in Dewi's attitude. The first meeting was started by a topic about teenage problem. Here, Danny showed drastically different attitude. He was very active. When the writer asked the students to elicit as many teenage problems as they can, Danny was the one who could do it very well. He was able to describe the most problems as other, and also explain it in detail. He even tried to relate the problem he described with the experienced he had. In this session, Danny was the one who was the most stand out. When the writer went to another class activity, Egi started to show her capability. She was very good in analyzing teenage problem which was delivered by a recording. She listened very well and able to describe what happen to the boy in the recording in detail. In this meeting, the writer still could not discover Dewi's attitude and motivation towards the material. This material was conducted in the first and the second meeting.

In the third meeting, the material was about past tense and past continuous. The writer started the meeting with a game. Students had to sit in a group, and wrote as many regular and irregular verbs as they could. Dewi and Egi were in the same group. During the game, the writer finally saw the capability of Dewi. She was very cooperative with her team mates. She could take part very actively, even dominated. After the game, the writer tried to encourage the students to explain what they knew about past tense and past continuous. Similar with the previous meeting, Danny and Egi still showed their interest in answering the writer's question. Dewi was actually able to answer the writer's question. But at that time, she needed to do personal approach to her to make her wants to speak. The writer finally found out that actually Dewi had better grammar structure in speaking than Egi and Danny, but maybe she was only shy. Next, the writer distributed a worksheet about past tense and past continuous. Danny looked very keen in doing the exercise. He even finished the exercise very well without asking any question to the teacher. Egi also looked comfortable in doing the exercise, but the she asked several questions to the writer for many times. Actually, the writer felt that Egi has already understood about the grammar point, but all she wanted to do was just to confirm whether what she did was correct or not. It was different with Dewi. She remained silent while doing the exercise. Even though she could do it very well, her phase in doing the exercise is slower than any other students in class.

Based on the writer's opinion, the fourth meeting was the toughest and the most difficult for the student, because in this meeting the students had to be able to analyze a painting based on its color, shape, and light. Even though the writer has done the preteaching part for this material, the students still showed their confusion towards this material. Unfortunately, Dewi did not come to the class in this meeting. Therefore the writer could not observe her. The exercise for this material is to comment a famous painting painted by a famous painters, like Van Gogh, Seurat, Da Vinci, and so on. Students had to do this exercise in the form of group. Danny and his team mates found it difficult to do this exercise, but they preferred to do it orally. Whatever they have seen in the paintings, the directly reported it to the teacher. Meanwhile, Egi seems that she needed more time to focus and elicit the adjectives which can describe the painting.

The fifth meeting was the day of the test. Before the test was started, the writer conducted a review session for 60 minutes. At the review session, she have told the students that they would only have 20 minutes to do each test; reading, writing, and listening test. The students did not really ask a lot question in the review session, they may look like they were ready to do the test. The listening test was started first, continued by reading and writing was the last. After the students finished the test, the writer could directly give mark to the tests, and reveal the score. The scores that each student got were as follows:

\begin{tabular}{cccc}
\hline Listening test & Reading test & Writing test & $\begin{array}{c}\text { Students' } \\
\text { Name }\end{array}$ \\
\hline $\mathbf{1 0 0}$ & 87 & 100 & Egi \\
$\mathbf{8 0}$ & 87 & 100 & Dewi \\
$\mathbf{1 0 0}$ & 100 & 100 & Danny \\
\hline
\end{tabular}

(source : http://www.odinplus.ef.com [2])

After the writer got the result of the test, she could finally analyze the correlation between students' performance and the result they got in the test. We are going to start from Egi. To sum up, Egi is very self-confident and quiet risk taking. She always takes part actively in answering the teacher's question to the students. In addition, the writer assumed that there is an integrative motivation inside her. It looks like she puts a lot of interest in the western culture as well. The way she speaks also shows the accent of British people, and she always tries her best to speak in that accent. The test result showed that Egi is just above average for this level. Her imperfect score of the reading maybe because of her hesitation in deciding which one is correct. This attitude was showed when she was doing exercise of past tense and past continuous. While Danny is more imaginative, he was capable in showing good vocabulary skill. The writer could observe this attitude in the first meeting, when he asked the students to try giving solution on each teenage problem. Danny was the one who could deliver a very good solution with an excellent story plot as well. Danny's introvert personality does not affect him in getting a totally perfect score. The writer implies that his instrumental motivation plays important role for his result. His characteristic when participating in class activity also supports the result he got. Also, the writer sees an adventuresome side of Danny. The "adventuresome" here mean the adventure of language and world knowledge. When we were studying about commenting a painting, Danny talked like he knew the background of each of the 
painting that he analyzed. The writer sees that his world knowledge helps him in getting the fantastic score. Meanwhile, the writer assumes that Dewi's imperfect scores are caused by her hesitation in speaking and communicating with the teacher. Compared to the others, Dewi is only the one who remained silent in the class, but has the best grammar structure in speaking. Her excellent grammar obviously supports her writing test to be outstanding. The writer also sees that Dewi was sometimes a bit uninterested in learning in class. But there is a positive attitude that other does not have but her, she is very tolerant of ambiguity. When the writer asked the students to with other student, she was always willing to help her friend who finds difficulties. The writer sometimes found her discussing and helping her friend with the material they were working on.

\section{CONCLUSION}

Based on the analysis, the writer found that there are some attitudes and motivation that makes the student success in learning. The writer sums up that there are several attitude that support this goal, high curiosity, talk active, lack of hesitation, and self-confident. The writer found that Danny who got all perfect scores in the test have those attitude. His introvert side does not also affect his success. $\mathrm{He}$ is also high motivated in learning L2. The most appealing one is the instrumental motivation. While Egi still sometimes shows her hesitation toward the target language she is doing. That is why she does not get perfect score in her reading test. In addition, her integrative motivation still supports the rest of perfect score. The last is Dewi, her excellent grammar structure only helps her to get perfect score on writing. According to the observation, the writer had to encourage her more and give her personal approach so she could speak her mind and communicate her problem. In the class, she seems keen in discussing in group rather than asking directly or personally to the teacher. She sometimes shows her hesitation and risk-avoiding. The writer implies that those characters still becomes her boundaries in learning.

\section{REFERENCES}

[1] Ellis, R. (1997). Second Language Acquisition. Oxford: Oxford University Press

[2] First, E. E. (n.d.). ODIN+. Retrieved July 1, 2015, from ODIN+ Teachers' Page: http://www.odinplus.EF.com

[3] Lightbown, P. M., \& Spada, N. (2006). How Language are Learned. Oxford: Oxford University Press

[4] Troike, M. S. (2012). Introducing Second Language Acquisition. Cambridge: Cambridge University Press. 